\title{
I. Annalistisk indholdsfortegnelse
}

1968

Grundtvig og Jylland. Foredrag ved Grundtvig-Selskabets årsmøde 1967. Af professor, dr. phil. Gustav Albeck, Århus . . . . . . . . . . . . . . . . .

Familiestriden i $1872-73$ om N. F. S. Grundtvigs efterladte papirer. Ved bibliotekar, cand.mag. Steen Johansen, København . . . . . . . . . . . . . . . . .

Hvorledes kom Grundtvig til at oversatte Saxo og Snorre? Af bibliotekar, cand.mag. Steen Johansen, København . . . . $S y v$ Beowulf-anmeldere. Af amanuensis, cand.mag. Andreas Haarder, Århus . . . . . . . . . . . . . . . . . . .

$65-75(90-91)$

Fra Grundtvig-litteraturen

Uffe Hansen: Grundtvigs Salmedigtning. Dens Historie og Indhold. III. 1851-1872. Anmeldt af universitetslektor, cand.mag. Kristian Kjar, Gøteborg . . . . . . . . . . .

English summaries. By amanuensis, cand. mag. Andreas Haarder, Århus . . . . . . . . . . . . . . . . . . .

$86-88(90)$

89-91

\section{Tillag}

Grundtvig-litteratur 1963-68. Ved universitetsadjunkt, cand. art. Aage Jorgensen, Århus . . . . . . . . . . . . . . . . .

Beretning om Grundtvig-Selskabets virksomhed 1967-68. Af biskop, dr. theol. Henning Høirup, Århus . . . . . . . . . . . Til medlemmerne af.Grundtvig-Selskabet. Af Gustav Albeck . .

\section{9}

Grundtvig et la France. Par prof. dr. Erica Simon, Lyon. Med et udførligt resumé på dansk . . . . . . . . . . . . . . . . .

Grundtvig og Shakespeare. Af Morten Bredsdorff.

Debatten om Grundtvig og Kierkegaard. En kritisk gennemgang af Hellmut Toftdahl . . . . . . . . . . . . . . . Fra Grundtvig-litteraturen

En Højskolevinter. Elevdagbog fra Provisorieårene i 1880erne udgivet af Roar Skovmand. Anmeldt af Uffe Grosen . . Årbog for Dansk Skolehistorie, 1967. Anmeldt af Uffe Grosen . Slagtens spor. Enok Mortensen: The Danish Lutheran Church in America. Anmeldt af prof. Ph. D. Johannes Knudsen . . . . . 
Helmut Toftdahl: Kierkegaard forst-og Grundtvig så. Anmeldt af William Michelsen . . . . . . . . . . . . . .

95-102 (107-109)

Beretning om Grundtvig-Selskabets virksomhed 1968-69 . . . . .

1970

Villiam Gronbak. Af dr. William Michelsen . . . . . . . . . . .

Werner G. Görnandt. Af dr. Henning Høirup . . . . . . . . .

Den lige linje $i$ Grundtvigs religiøse udvikling. Af Jakob Rod, Hylke . . . . . . . . . . . . . . .

Grundtvig oversat til tysk Salmetradition. Af L. L. Albertsen, Århus

$33-45(45-46)$

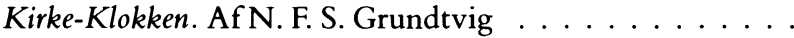

Kirke-Klokken 1845. Af Karl Ronne . . . . . . . . . . . . . .

En omstridt Grundtvig-salme og dens forstadier. Af Th. Borup Jensen . . . . . . . . . . . . . . . .

De Levendes Land. En fortolkning. Af Niels Egebak . . . . . .

Grundtvigs forhold til Sverige. Af Valdemar Nielsen

49-55 (96-97)

$56-66(97)$

67-77 (97-98)

$78-88(99-100)$

Fra Grundtvig-litteraturen

Jorgen Elbek: Litteraturen $i$ dag. Anmeldt af William Michelsen

$91-93(100)$

Grundtvigs skoleverden ved K.E. Bugge. Anmeldt af Soren Holm . . . . . . . . . . . . . .

Christian Thodberg: En glemt dimension $i$ Grundtvigs salmer. Anmeldt af P. G. Lindhardt . . . . . . . . . . . . . . .

93-94 (100-101)

94-95 (101-102)

\section{Tillaeg}

Beretning om Grundtvig-Selskabets virksomhed 1969-70. Af Henning Høirup . . . . . . . . . . . . . . . . .

1971

Grundtvigs rimbreve, Af Gustav Albeck

Striden mellem Grundtvig og H. C. Ørsted. Af Erland Jessen . .

Von einem "Echten Deutsch" und von den "Deutschen Sprachen des Herzens", von Horst Nägele . . . . . . . . . . . . . . . .

Om "Egte Tydsk" og om de tyske "Hjertesprog" $i$ Grundtvigs forestillingsverden. Af Horst Nägele . . . . . . . . . . . .

Om at tilskrive sig Troens rare klenodie. Af Niels Egebak .

Lingvistik, systemdigtning og Grundtvig. Af Hellmut Toftdahl

98-106 (129-130)

\section{Fra Grundtvig-litteraturen}

Tord Ehnevid: Församlingsetik. Anmeldt af P. G. Lindhardt . . 111-112 (130-131) 
Kontroverse um Grundtvig und Kierkegaard I-II. Anmeldt af Hellmut Toftdahl

Intepreters of Luther. Anmeldt af Viggo Mortensen . . . . . . .

Fra modernisme til nymarxistisk kritik. Anmeldt af William Michelsen . . . . . . . . . . . . . . . . . . . . . . 120-121 (133-134)

Aage Henriksen: Gotisk tid. Anmeldt af William Michelsen . . 121-126 (134-135)

\section{Tillag}

Grundtvig-litteratur 1969-1970. Ved Karen Højer-Pedersen . . . $107-110$

Beretning om Grundtvig-Selskabets virksomhed 1970-71. Af Henning Høirup . . . . . . . . . . . . .

$136-137$

1972

Professor Kemp Malone 1890-1972. Af Gustav Albeck . . . . .

Det moderne menneskes situation og Grundtvigs antropologi. Af William Michelsen . . . . . . . . . . . . . . .

Et forslag til en grundtvigsk lard skole 1832. Af Henning Heile-

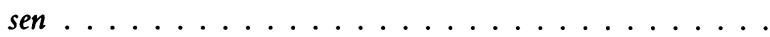

Grundtvig-manuskripter og grundtvigiana i Det kgl. Bibliotek erhvervet 1963 - maj 1972, ved bibliotekar Steen Johansen, København . . . . . . . . . . . . . . . .

Hil dig, Frelser og Forsoner!, et nærlæsningsforsøg, af William Michelsen . . . . . . . . . . . . .

$40-50(71)$

$51-57(71-72)$

Fra Grundtvig-litteraturen

Dem Menschen zugute. Götz Harbsmeier zum 60. Geburtstag. Anmeldt af Regin Prenter . . . . . . . . . . . . .

Holger Kjar: Højskolens Grund. Anmeldt af William Mi-

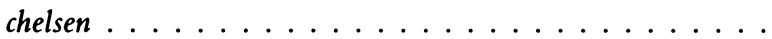

$58-62(72-73)$

64-65

Ebbe Klovedal Reich: Frederik. Anmeldt af Gustav Albeck . . .

Beretning om Grundtvig-Selskabets virksomhed 1971-72. Af Henning Høirup . . . . . . . . . . . . . . .

\section{3}

Pastor Valdemar Nielsen, 1886-1972. Af Henning Høirup . . . . $6-8$ Det internationale Grundtvig-seminar "A Century after Grundtvig “ 13.-19. august 1972. Af William Michelsen . .

Grundtvigs udfordring til moderne theologi. Af Regin Prenter .

Grundtvig og Soren Kierkegaard. Af Hellmut Toftdahl . . . . . .

En naturfilosof efter Grundtvigs hjerte. Af Ejvind Larsen . . . . .

A Century after Grundtvig. By William Michelsen . . . . . . . .

Grundtvig, an Introduction. By Kaj Thaning . . . . . . . . . . 
The Rise and Growth of the Danish Folk High School. By Roar

Skovmand . . . . . . . . . . . . . . . .

The Folk High Schools, their Role and Activity today. By Thomas Rordam . . . . . . . . . . . . . . . . . . .

The Dominant Peoples in History according to Grundtvig and Hegel. By Tord Ehnevid . . . . . . . . . . . . . . . . .

Grundtvig and Germany. By professor, dr.theol. Götz Harbsmeier . . . . . . . . . . . . . . . . . .

The Grundtvigian "Folkelighed " and Leopold Senghor's "Négritude". By professor, dr. Erica Simon . . . . . . . . . . . . .

The International People's College at Elsinore. By Peter Manniche . . . . . . . . . . . . . . . . .

Grundtvig, The Danish Folk High School and the Developing Countries. By Svend Erik Bjerre . . . . . . . . . . . . . .

Det internationale Grundtvig-Seminar 13.-19. august 1972. Forkortet dansk gengivelse af foredragene ved William Michelsen . . . . . . . . . . . . . . . . . .

Fra Grundtvig-litteraturen . . . . . . . . . . . . .

Götz Harbsmeier: Wer ist der Mensch. Anmeldt af Hellmut Toftdahl . . . . . . . . . . . . . .

Grundtvig til undervisningsbrug. Anmeldt af William Michelsen

Supplement til Grundtvig-Studier 1972

Holger Kjar: Højskolens grund. Reviewed by William Michelsen . . . . . . . . . . . . . . . .

Årberetning for 1972-73. Af William Michelsen . . . . . . . . .

Leif Garsdal. Af William Michelsen . . . . . . . . . . . . .

Grundtvig og mystikken. Af Hellmut Toftdahl

Digteren Goldschmidt og Grundtvig. Af Morten Bredsdorff. . . .

Om Grundtvig som europaer. Af William Michelsen . . . . . . .

Den danske salme i Amerika. Af Enok Mortensen . . . . . . . .

Grundtvig-litteratur 1971-1973. Af Aage Jorgensen . . . . . . .

76-84

Fra Grundtvig-litteraturen

Jorgen Elbek: Grundtvigs atten provear. Anmeldt af Gustav Albeck . . . . . . . . . . . . . . .

Ejvind Larsen: Grundtvig - og noget om Marx. Anmeldt af Kaj

Thaning . . . . . . . . . . . . .

$86-90(95)$

\section{Tillag}

Årberetning. Af William Michelsen . 
Var Grundtvigs nadversyn luthersk? Af Christian Thodberg . . .

Deltheden hos Grundtvig efter 1832. Af Jorgen Elbek . . . . . .

Guds Ord besunget af Grundtvig. Af Uffe Hansen . . . . . . . .

Fra Grundtvig-litteraturen

P. G. Lindhardt: Konfrontation. Grundtvigs prædikener i kirkeåret 1854-55 på baggrund af Kierkegaards angreb på den danske kirke og den "officielle " kristendom. Akademisk forlag. 1974. Anmeldt af William Michelsen . . . . . .

Andreas Haarder: Beowulf. The appeal of a poem. Akademisk forlag. 1975. Anmeldt af Jens Kruuse . . . . . . . . . . . . .

Tillag

Modtagne publikationer

Årsberetning. Af William Michelsen . . . . . . . . . . . . .

1976

Was könnte Grundtvig heutzutage für reformierte Christen bedeuten? Von G. F. W. Herngreen, Holland . . . . . . . . . . .

Hvad kunde Grundtvig i dag betyde for reformerte kristne? Af G. F. W. Herngreen (Forkortet gengivelse) . . . . . . . . . .

Nogle bemarkninger vedrorende en samlet udgave af Grundtvigs dagboger. Af Gustav Albeck. . . . . . . . . . . . . . . . .

Om Grundtvigs tidsopfattelse. Af William Michelsen . . . . . . .

Bibliographie über Grundtvig-Literatur in nicht-skandinavischen Sprachen. Von Eberhard Harbsmeier . . . . . . . . . . .

$52-64$

Fra Grundtvig-litteraturen

Barnedab $i$ kirken. Ritualforslag ved Kirkeligt Samfunds udvalg 1974 og Nadver $i$ kirken. Ritualforslag ved Kirkeligt Samfunds udvalg 1976. Anmeldt af Th. Lyby Christensen

Christa Kühnhold: Der Begriff des Sprunges und der Weg des Sprachdenkens. Anmeldt af Hellmut Toftdahl . . . . . . . . .

Årsberetning 1975-1976. Af William Michelsen . . . . . . . . .

1977-78

FOR SAMMENHÆNGENS SKYLD. Ord og motiver i Grundtvigs salmer og prædikener. Ved professor dr. phil. Christian Thodberg, Institut for Praktisk Teologi, Aarhus Universitet. Arbejdsblad til Lise Helwegs artikel indlagt.

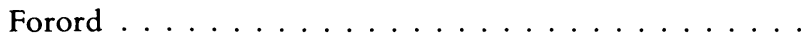


Ebbe Fibiger: Jesus Kristus - Guds Ord . . . . . . . . . . 10-36 (299-300)

Morten Mortensen: Helligånden, Guds røst på jord . . . . .

Erik Krebs Jensen: Hjertets gudbilledlighed . . . . . . . . . . . . . . . . . . . . . . . . . .

Henning Sørensen: Troens grund . . . . . . . . . . . . .

97-123 (302-303)

Christian Højlund: Håbets mellemrum - Nutid og fremtid i Grundtvigs tolkning af håbsbegrebet . . . . . . . . . . .

Valdemar Leth Ludvigsen: Herrens bøn "Fadervor" . . . . .

Leif Kallesen: Nadverelementerne og billedsynet . . . . . . .

Lise Brandt Fibiger: Grundtvigs væksttanke - Fra menneskelivets begyndelse til dets fuldendelse . . . . . . . . . .

Lise Helweg: Til Glæde for Graad - Om V-strukturen i

Grundtvigs "håbssalme» . . . . . . . . . . . . . . . . . 247-259 (306-307)

Christian Thodberg: Den grundtvigske arv: Christian Hostrup som prædikant med særligt henblik på de grundtvigske elementer . . . . . . . . . . . . .

124-157 (303-304)

$158-185$ (304)

$16-212(305)$

$213-246(305-306)$

260-292 (307-308)

\section{Fra Grundtvig-litteraturen}

En amerikansk Grundtvig-oversattelse. Selected Writings of N. F. S. Grundtvig, edited by Johannes Knudsen. Anmeldt af Niels Lyhne Jensen . . . . . . . . . . . . . . . .

Bernd Henningsen: Die Politik des Einzelnen. Ludvig Holberg, Søren Kierkegaard, N. F. S. Grundtvig. Anmeldt af Viggo Mortensen, Århus . . . . . . . . . . . . . . . . . . . . . . . .

Rettelse til Grundtvig-Studier 1976 . . . . . . . . . . . . 293-296 (308-309) 296-298 (309-310)

Modtagne publikationer . . . . . . . . . . . . . 312

Årsberetning 1976-1977. Af William Michelsen . . . . . . . . 313

Meddelelser fra redaktionen . . . . . . . . . . . . . 1979

Götz Harbsmeier 1910-1979.

Af Kaj Thaning . . . . . . . . . . . . . . . . .

"Odin og Saga " genfundet. En Grundtvig-tekst fra 1810 udgivet af Flemming Lundgreen-Nielsen . . . . . . . . . . .

Grundtvig og hans samtids tankemåde. Overvejelser over Grundtvigs stilling i dansk åndsliv af William Michelsen . .

Grundtvigs erkendelsesteori. Om forholdet mellem tro og fornuft i tidsskriftet "Danne-Virke» (1816-19).

Af Henrik Fibak Jensen .

Fra Grundtvig-litteraturen

Enok Mortensen: Schools for Life. (Danish-American Heritage Society, 1977.) Anmeldt af Kaj Thaning . . . . . . . . . . . 
Vartovbogen 1975-1976-1977. Anmeldt af Th. Lyby Chri-

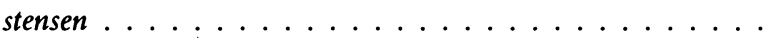

Vartovbogen 1978. Anmeldt af Viggo Mortensen . . . . . . . .

Dansk Tidsskrift Index, 61. og 62. årgang, 1975-76. Anmeldt af Aage Jorgensen . . . . . . . . . . . . . . .

\section{Tillag}

Grundtvig-litteratur 1974-1979. Af Aage Jorgensen . . . . . . .

Årsberetninger af William Michelsen . . . . . . . . . . .

"Rød og hvid i Billedsalen. " Grundtvigs døds- og mindedigte

Videnskab og hverdagssprog. Grundtvigs betragtning af modersmålet $\mathrm{i}$ teori og praksis, belyst ved hans afhandling Om Ordsprog, 1817. Af Bodil Schmidt . . . . . . . . . .

\section{Fra Grundtvig-litteraturen}

N.F. S. Grundtvigs Dag- og Udtogsbøger I-II, udgivet af Gustav Albeck. Anmeldt af Christian Thodberg . . . . . . . . .

Historiefilosofi og antropologi. - Poul Behrendt: Viljens former. Anmeldt af Mogens Bjerring-Hansen . . . . . . . . . . .

\section{1}

Den " mageløse opdagelse"s tilblivelse. Af Kaj Thaning . . .

"Rød og hvid i Billedsalen". Grundtvigs døds- og mindedigte

II. Af Flemming Lundgreen-Nielsen . . . . . . . . . . . .

Fra Grundtvig-litteraturen

Grundtvig. Tekstudvalg ved K. E. Bugge. Anmeldt af Aage Jorgensen . . . . . . . . . . . . . .

Vartovbogen 1980. Anmeldt af Viggo Mortensen. . . . . . . . 
Om Grundtvigs poetik med særligt henblik på den bibelske inspiration. Af Christian Thodberg . . . . . . . . . . . .

Antropologi og poetik $i$ Verdenskroniken 1814. Af Knud Sølvbjerg. En redegørelse af William Michelsen . . . . . . . . . .

Grundtvig og Det litterare Selskab 1805-1822. Af Flemming Lundgreen-Nielsen

Fra Grundtvig-litteraturen. To anmeldelser:

Sandheden som fremmedlegeme? Helge Grell: Skaberordet og billedordet. Anmeldt af Hellmut Toftdahl . . . . . . . . . .

Fortællingen i Focus. Vartovbogen 1981. Anmeldt af Viggo Mortensen . . . . . . . . . . . . .

Grundtvig-Selskabets årsberetning. Af Christian Thodberg . . . .

1983

Sin samtids kritiker - N. F. S. Grundtvig 1783-1872. Af William Michelsen . . . . . . . . . . . . . . . .

Mytologen Grundtvig. Af Jorgen Elbek . . . . . . . . . . . . $7-28$ (94-97)

$\mathrm{Du}$, som går ud fra den levende Gud. Af Peter Balslev-Clausen .

Drommen om Skolen i Soer. Af Gustav Albeck . . . . . . . . . . 69-86 (99-100)

Fra Grundtvig-litteraturen

Folkehøjskolen som forbillede for tyskere. Af Roar Skovmand . . . . . . . . . . . . . . . . . . . .

$87-89(100-101)$

Anmeldelse af: Harald Behrend und Norbert Lochner: Geschichte und Gegenwart der Heimvolkshochschulen in Dänemark, Osnabrück 1966.

Reformation af grundtvigianismen. Af Viggo Mortensen

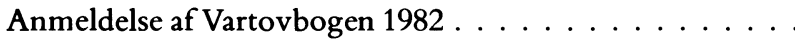

Modtagne boger . . . . . . . . . . . . . . . . .

90-92 (101-102)

Grundtvig-Selskabets årsberetning. Af Christian Thodberg . . . .

\section{4}

Forord. Af redaktionen . . . . . . . . . . . . . . .

Grenzen der Menschheit. Et Grundtvigmanuskript på tysk, med indledning og oversættelse af William Michelsen . . . Menneskets granser. . . . . . . . . . . . . . . . Injuriesagen mod Grundtvig 1825-1826. Af Grete Bøje . . . . . Om Grundtvigs Sang-Vark I-V. Af Henning Høirup . . . . . . Om digteren Grundtvig. Af Finn Stein Larsen . . . . . . . . . . Om Grundtvig og nutiden. Af William Michelsen . . . . . . . Fra Grundtvig-litteraturen . . . . . . . . . . . . 
N.F.S.Grundtvig: Om Mennesket i Verden, udg. af K. B. Gjesing. Anmeldt af Hellmut Toftdahl. . . . . . . . . . $88-89(140)$

En amerikansk disputats om Grundtvigs hermeneutik. Anmeldt af Hejne Simonsen . . . . . . . . . . . . . . . . . . "Skolefrihed". Eckhard Bodensteins Skolefrihed, in Dänemark.

Anmeldt af Vilhelm Nielsen . . . . . . . . . . . . . . . .

Regeneration af Grundtvigianismen, Vartovbogen 1983. Anmeldt af William Michelsen . . . . . . . . . . . . .

Grundtvig-litteratur 1979-1983. Ved Aage Jorgensen. . . . . . . Årsberetning for Grundtvig-Selskabet. Af Christian Thodberg . .

1985

Forord.

Clara. Af N. F. S. Grundtvig . . . . . . . . . . . . .

Hvem var Clara? 1-3. Af Kaj Thaning . . . . . . . . . . . . . .

Den unge Grundtvig og Norge. Af Gustav Albeck . . . . . . . . $11-46(92-96)$ $47-66(96-99)$

Introduktion til Danne-Virke. I. Af William Michelsen . . . . . 67-78 (99-101)

\section{Fra Grundtvig-litteraturen}

Myter og mundtlighed. Af Vilhelm Nielsen . . . . . . . . . .

Socialetikken og det grundtvigske. Af Viggo Mortensen . . . . . .

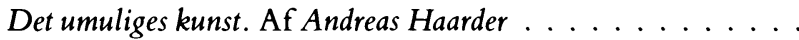

Grundtvig i dag. Af William Michelsen . . . . . . . . . . . .

Årsberetning for Grundtvig-Selskabet. Af Christian Thodberg . .

87-89 (102-103)

90-91 (103)

Modtagne bøger . . . . . . . . . . . . . .

\section{6}

Skabt $i$ Guds Billede. En lidet kendt udredning af Grundtvig

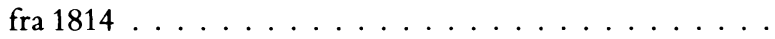

Grundtvigs skovoplevelse i 1811 og prædikenerne over Peters fiskedræt i tiden, der fulgte. Af Christian Thodberg . . . . .

Om Grundtvigs tankning og den nyere tids filosofi. Introduktion til Danne-Virke II. Af William Michelsen . . . . . . . . . .

Adskillelse og vekselvirkning. Om Grundtvigs syn på folkelighed og kristendom. Af Theodor Jorgensen . . . . . . . . .

$11-55(96-99)$

$56-70(99-102)$

$71-83(103)$

\section{Fra Grundtvig-litteraturen}

N. F. S. Grundtvig: Blik paa Poesiens Historie og Bernhard Severin Ingemann. Udg. af Flemming Lundgreen-Nielsen. Anmeldt af Gustav Albeck . . . . . . . . . . . . . . . . . .

84-86 (103-104)

Frederik Nielsen: N.F.S. Grundtvigip Tussiusiai kalaallisuunngiortitat. Nuuk 1985. Anmeldt af Signe Michelsen . . .

$87-90(105)$ 
Kirsti Aasen: Alle mine kilder. Anmeldt af Helge Baden Niel-

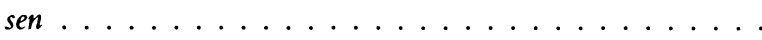
Vartovbogen 1985. Anmeldt af Viggo Mortensen 91-93 (106)

Arsberetning for 1985-86. Af Christian Thodberg 94-95 (106) 